\title{
CONFECÇÃO DE HISTÓRIAS EM QUADRINHOS NA MELHORIA DO APRENDIZADO DE QUÍMICA NO ENSINO MÉDIO
}

\section{PREPARATION OF CARTONS IN THE IMPROVIMENT OF CHEMISTRY LEARNING IN HIGH SCHOOL}

Maria das Graças Gomes

Universidade Federal do Ceará

Departamento de Química Analítica e Físico-Química / Email:gracinha@ufc.br

Francisca Mayara Santos de Alencar / mayshs@gmail.com

David Oliveira Diógenes / david.diogenes10@yahoo.com.br

Armando Diego Lima de Freitas / adiego13.dl@gmail.com

Dheyla Passos Matias / dheylamatias@gmail.com

Universidade Federal do Ceará

Departamento de Química Analítica e Físico-Química

Curso Licenciatura em Química

\section{RESUMO}

As Histórias em Quadrinhos (HQs), no passado, consideradas más influência na educação de jovens e adolescentes, foram reconhecidas pelos Parâmetros Curriculares Nacionais, como uma ferramenta didática que vai além de simples leitura, permite explorar o imaginário dos estudantes, tornando aulas dinâmicas. O presente trabalho tem como objetivo usar a confecção de HQs na aprendizagem de conceitos químicos. A atividade foi desenvolvida em escolas publicas de Fortaleza, onde os bolsistas do Programa Institucional de Bolsa de Iniciação á Docência PIBID-Química orientaram os estudantes no desenvolvimento das estórias. A elaboração da revista foi dividida em duas etapas: na primeira selecionaram-se os conteúdos a serem trabalhados. Em seguida, confeccionados textos contendo as fundamentações teóricas e suas aplicabilidades no cotidiano. Os textos foram apresentados aos alunos das escolas que em sala de aula e em grupos, leram, discutiram e criaram suas estórias usando a imaginação, os conceitos químicos expostos e suas experiências de vida. Os estudantes tiveram a ajuda dos professores de português e artes. Foi realizada uma seleção das melhores estórias que foram incluídas na revista em quadrinhos do PIBID-Química, e distribuída entre estudantes participantes e as bibliotecas das escolas para serem utilizadas como material didático.

Palavras-Chave: Historias em Quadrinhos, Ensino de química, PIBID. 


\begin{abstract}
The cartons $(\mathrm{HQ})$, in times past was considered a bad influence in the education of young people and adolescents, was recognized by the NCP as an educational tool that goes beyond simply reading, it allows to explore the imagination of students, making the classes more dynamic and less formal. This paper aims to use the production of carton in learning of chemical concepts. The activity was developed in public schools in Fortaleza, where PIBID Chemistry guided the students in the development of stories. The preparation of the magazine was divided into two stages: the first selected the contents to be worked out. Then made texts containing the theoretical foundations and their applicability in everyday life. The texts were presented to the students of the schools in class divided into groups, and after reading and discussing; they created stories using their imagination, the exposed chemical concepts and their life experiences. In the preparation of the texts, Portuguese and arts teachers helped the students. A selection of the best stories that were included in the revised PIBID Chemistry carton was made and distributed among the participating students and school libraries. Magazines are used as teaching material for use by teachers.
\end{abstract}

Keywords: $\mathrm{HQ}$, chemistry learning, PIBID. 


\section{Introdução}

As disciplinas do Ensino Médio que abordam as ciências exatas, mas especificamente a Química, a Física bem como a matemática, abordam conteúdos que apresentam um elevado grau de abstração. Por ser o primeiro contato mais de perto com estas disciplinas, esse fato leva aos alunos pensarem que os assuntos abordados estão bem distantes do seu dia-a-dia provocando assim, uma antipatia ou aversão as mesmas. De acordos com depoimentos de professores de ensino médio da rede pública, a segunda matéria que apresenta maior grau de abstração é a química sendo a primeira a física (FERREIRA et al.,2010).

Essa aversão a Quimica se deve em parte a maneira como é transmitida, pois os alunos a veem como complicadas fórmulas e conceitos a serem memorizados, sem ter nenhuma aplicabilidade em sua vida prática. De acordo com os Parâmetros Curriculares Nacionais do Ensino Médio (PCNEM, BRASIL, 2000) do Ministério de Educação e Cultura (MEC), em relação a novas metodologias do ensino, pontuam estes que deve-se haver uma renovação tanto nos conteúdos como nas metodologias empregadas. Cabe então aos professores do $9^{\circ}$ ano do ensino fundamental e do ensino médio começar a mudar ou renovar suas metodologias de ensino.

É grande a necessidade da área docente em promover a renovação ou novas metodologias que busquem e atraiam a atenção e o interesse dos alunos pela Ciência, mais precisamente pela Ciência Química, cabe ao professor desmistificar o que os alunos pensam da Ciência (SILVA, 2011). O uso somente de aulas simplesmente expositivas não trará a transformação necessária, e seguindo a metodologia tradicional dificilmente se despertará nos alunos o desejo espontâneo pelas Ciências.

Uma das principais maneiras de chamar a atenção e desenvolver o processo de ensino e aprendizagem é o uso da ferramenta lúdica. Jogar é uma atividade natural do ser humano, desde criança estas atividades são parte constante em nossas vidas (ROLOFF, 2010). De acordo com repositório de significados, conceitos e definições (GUIMARÃES e CABRAL, 2014) a palavra lúdico vem do latim Ludos e significa jogos, diversão, entretenimento. Através do lúdico o ser humano consegue descrever e recriar o conhecimento a sua volta. Segundo Roloff (2010, p. 01),

... a função educativa do jogo oportuniza a aprendizagem do indivíduo: seu saber, seu conhecimento e sua compreensão de mundo. Está ai o papel do professor de utilizar a melhor maneira possível o lúdico para desenvolvimento do saber e envolvimento dos alunos no processo de aprendizagem com objetivos e orientações bem determinadas. 
O atual desafio dos docentes das disciplinas de ciências é transformar as atividades lúdicas não em mero divertimento e sim em meios altamente potenciais de ensino e aprendizagem (CHATEAU, 1984). Cabe-os desenvolver e propor meios para o qual haja a melhoria do ensino, aproveitando de melhor maneira possível o uso da ferramenta, tendo objetivos determinados, e orientando para que o sujeito passe a um ser pensante e agente transformador da sociedade que o cerca.

As histórias em quadrinhos (HQ's), geralmente são apresentadas em desenhos, seguindo uma sequencia lógica (por isso também são conhecidas como arte sequencial), contendo pequenos textos (concisos e diretos) dentro de pequenos balões. No princípio houve muita objeção com relação ao uso de HQ's, estes não eram bem-vistos, e segundo alguns psicólogos poderiam causar até preguiça mental. Muito combatidos por décadas, durante os anos 90 foram aceitos e passaram a ser recomendados pela LDB e pelos parâmetros curriculares nacionais (SANTOS et al.,2008) sendo incorporados no meio acadêmico, sendo uma ferramenta de linguagem entre imagens e as palavras. Segundo Testoni e Abib (2004, p. 04),

as Histórias em Quadrinhos possuem uma gama de funções lúdicas e linguísticas que podem ser úteis para o processo de ensino e aprendizagem. Não menos importante é o conjunto de processos cognitivos que a leitura de um Quadrinho permite ao seu leitor. A interpretação dos códigos mistos que permeiam a $\mathrm{HQ}$ exige uma atenção complexa do indivíduo, tendo em vista o grande número de regras e convenções estabelecidas para uma leitura correta da mesma. Durante o desenvolvimento do enredo, o leitor poderá utilizar sua capacidade de análise, síntese, classificação, decisão e tantas outras atividades mentais que se fizerem necessárias a uma compreensão correta da narrativa.

As HQ's promovem o hábito da leitura e a criatividade, e esta é de forma prazerosa e não cansativa, uma vez que estes não apresentam textos muito extensos e a linguagem utilizada é simples e de fácil compreensão. Atualmente as HQ's deixaram de ser apenas brincadeira, e hoje se encontram presentes em livros didáticos, provas de processos seletivos, e etc. (Almeida e ATAIDE, 2011). Considerando suas características são amplamente utilizados como ferramenta no ensino de conceitos químicos, enquadrandose como estratégia didática, onde se emprega o lúdico.

Neste contexto o grupo Pibid-Quimica da UFC idealizou a confecção de HQ's como forma de transmissão de conhecimento químico, auxiliando na aprendizagem e ao mesmo tempo promovendo a desmistificação da química como ciência difícil de entender.

\section{Metodologia}

Utilizaram-se Histórias em Quadrinhos (HQ), tipo 'gibi', para revisar ou mesmo apresentar diversos conteúdos de Química. O material didático $(\mathrm{HQ})$ foi elaborado pelos alunos de escolas públicas da cidade de Fortaleza, capital do Ceará. A primeira edição, ou número 1, da revista em quadrinhos denominada de QUIMIUM foi com a participação 
das escolas Liceu de Messejana e Liceu do Conjunto Ceará ; já na segunda edição ou número 2, participaram o Colégio Estadual Justiniano de Serpa. Em todas as escolas contou-se com o auxílio dos bolsistas de química do Programa Institucional de Bolsas de Iniciação a Docência- PIBID do Governo Federal, que são alunos do curso de Licenciatura em Química da Universidade Federal do Ceará.

Iniciou-se a construção da revista em duas etapas, na primeira os bolsistas do PIBID selecionaram os conteúdos de Química a serem trabalhados verificando o planejamento anual de cada escola, e após discussão entre os grupos de bolsistas e professores das escolas, selecionaram-se na primeira edição:

- 1ำ Ano: Fenômenos Físicos e Químicos; Ligação lônica e covalente; Ácidos e bases; Estequiometria.

- 2ํo Ano: Soluções e Colóides; Propriedades Coligativas; Cinética-Velocidade de Reação; Pilhas e baterias e Equilíbrio Químico.

- 3ํㅗㅇ Ano: Hidrocarbonetos; Ligações C, H e O; Funções Orgânicas; Isomeria e Biomoléculas.

Para a segunda edição:

- 1ํAno: Tabela Periódica, Modelos Atômicos, Métodos de Separação de Misturas, Misturas Homogêneas e Heterogêneas e Estados Físicos da Matéria.

- 2ํAno: Misturas, Unidades de Pesos e Medidas, Densidade, e Ligações Químicas.

$\mathrm{Na}$ primeira edição inicialmente selecionou-se três turmas, uma de cada ano ou série do ensino médio, distribuídas entre as duas escolas já citadas. Nesta edição além dos alunos da escola, teve a participação dos bolsistas Pibid. Os tópicos considerados de difícil assimilação foram designados aos bolsistas e foram estes: Estequiometria, Equilíbrio Químico, Cinética, Isomeria, e Biomoléculas. Aos alunos da escola foram designados os outros temas, sempre de maneira voluntária nas escolhas dos seus conteúdos, ou seja, a cada grupo de alunos eram apresentados 3 temas, que tinham relação com a sua turma ou ano e a escolha final eram deles.

Antes da confecção das "tirinhas", os alunos receberam um material didático a respeito dos temas escolhidos por eles elaborados pelos bolsistas do Pibid-Quimica. Neste eram apresentados os conceitos de forma contextualizada usando exemplos do cotidiano deles. Dúvidas foram elucidadas numa conversa bem informal e então os grupos divididos de acordo com a escolha dos temas.

Na segunda edição realizada no Colégio estadual Justiniano de Serpa, a atividade foi realizada com 7 turmas de primeiro ano e com 4 turmas de segundo ano, totalizando 11 turmas participantes. A escola é de tempo integral e os temas escolhidos abrangem tanto as turmas de primeiro como as de segundo ano, pois estes tem a disciplina de Química dividida em vários módulos contendo ambos os assuntos que são revistos durante as séries do ensino médio. Da mesma forma foram distribuídos entre os alunos textos com as fundamentações teóricas e as suas devidas aplicabilidades. Nesta edição, 
também foram adicionadas histórias confeccionados por bolsistas de todas as escolas envolvidas naquele momento no programa (3). De posse dos textos os bolsistas os apresentaram aos alunos que em um segundo momento da atividade, dividiram-se em grupos e criaram suas próprias estórias usando a imaginação, seu cotidiano de forma criativa aplicando-os aos conceitos químicos expostos. Além dos bolsistas da Química, a segunda edição contou com o apoio e colaboração dos professores de português e artes.

\section{Resultados e Discussões}

$\mathrm{Na}$ confecção do material em sala de aula nas três escolas em estudo, foram usados apenas papel, canetas de ponta porosa e lápis de cor (ver figura 01). Nas histórias os alunos escolheram seus roteiros, abordaram temas do seu ambiente escolar e fora dele, como baladas, papos entre amigos, praia, e em algumas estórias estes demonstraram emoções e sentimentos de descoberta e admiração pelas ciências.
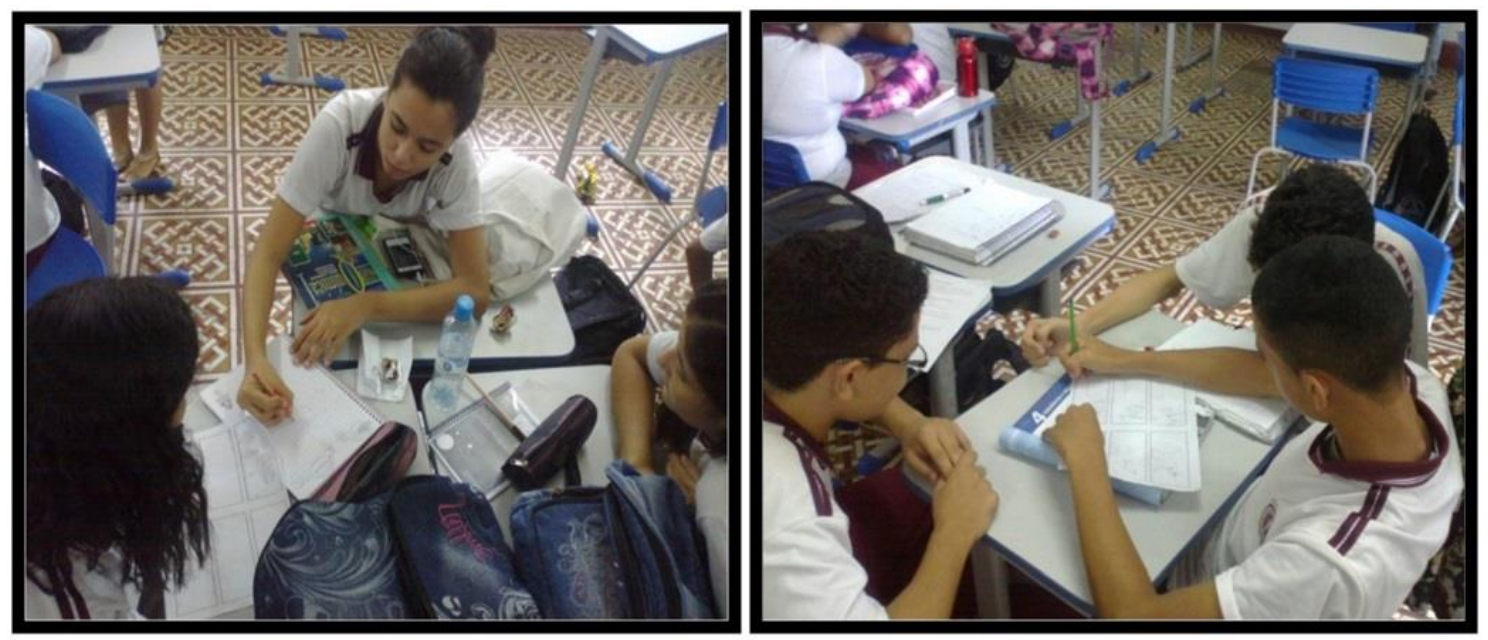

Fonte: O Autor

Figura 01: Alunos em sala de aula confeccionando as historinhas em quadrinhos.

Em todas as edições da revista em quadrinhos, as tirinhas elaboradas pelos alunos foram das mais diversas categorias, aulas experimentais e tradicionais, debates científicos, e bate-papo em sala de aula. A comédia foi uma tema presente, às vezes mais exagerado e outros mais discretos, tendo sempre uma boa dose de humor. O nível artístico também variou, alguns apresentaram desenhos ou caricaturas, outros tiveram influências dos mangás orientais, com traços fortes e bem desenhados, outros mais rudes, porém com forte expressão da mensagem a ser repassada (ver figuras 02 e 03). 

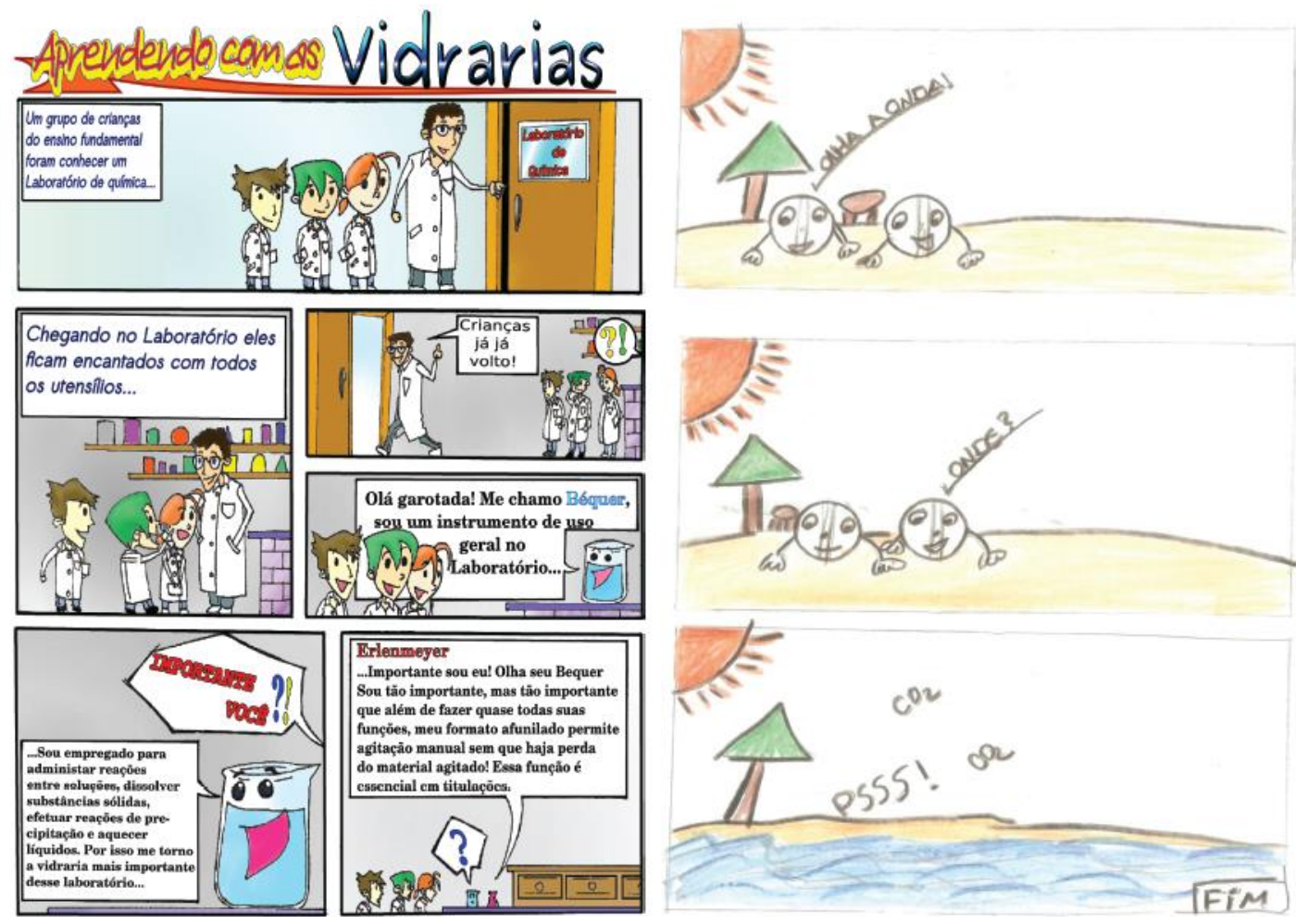

Fonte: Revista Quimium - PIBID Química / UFC - 1ª Ed. 2011.

Figura 02: Exemplo de uma tirinha criada pelos alunos da escola Liceu do Conjunto Ceará.
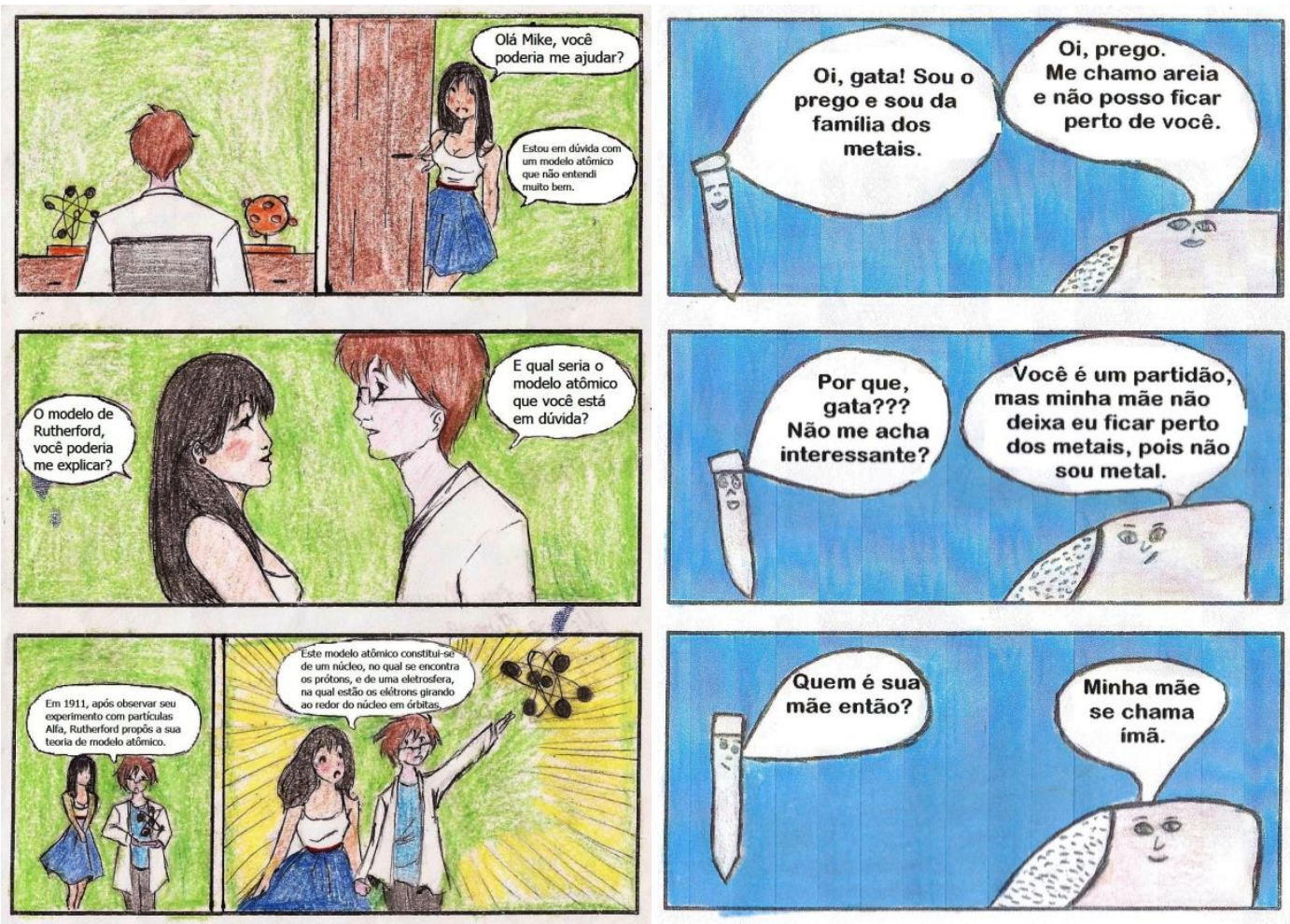

Fonte: Revista Quimium - PIBID Química / UFC - 2ª Ed. 2013

Figura 03: Tirinhas Confeccionadas pelos alunos do Colégio Estadual Justiniano de Serpa. 
Segundo as observações durante a aplicação desta atividade, a confecção das HQs colaborou para que os alunos das escolas envolvidas no trabalho uma série de habilidades e competências importantes para o seu desenvolvimento. Ao escrever o roteiro das histórias, os alunos foram orientados a usar as regras da língua portuguesa para especificar os conteúdos químicos, tendo o cuidado de repassá-los de maneira correta, clara e concisa, e a usar sua criatividade nas caricaturas, o que ajudou a transformar o trabalho interdisciplinar. Ao criar suas situações, o aluno passou a ser um ator ou personagem na difusão do conhecimento, e também detentor do saber, pois para repassar algo estes deveriam primeiro conhecer o assunto abordado. Estes produziram seu próprio material didático.

Outra habilidade adquirida pelos alunos foi à capacidade de trabalhar em grupo, já que as histórias eram um conjunto de ideias do grupo, e as tarefas eram distribuídas de acordo com habilidade pessoal de cada um, como por exemplo, a capacidade de desenhar, o de melhor letra, de melhor redigir o texto, entre outras. Também foi possível avaliar o grau de domínio dos conteúdos abordados e a maneira às vezes bem distinta de cada grupo de visualizar o mesmo conteúdo e expressá-los de maneira diferente, porém correta.

O momento da elaboração da revista, como citado já foi um aprendizado. De posse de todas as histórias, as melhores estórias foram selecionadas e juntamente com as estórias desenvolvidas pelos bolsistas confeccionou-se a revista QUIMIUM - Revista em Quadrinhos do PIBID-Química, contendo 18 histórias em quadrinhos (ver figura 04). Exemplares das duas edições foram distribuídos nas bibliotecas da escola, aos alunos participantes das estórias selecionadas e entre os bolsistas Pibid.

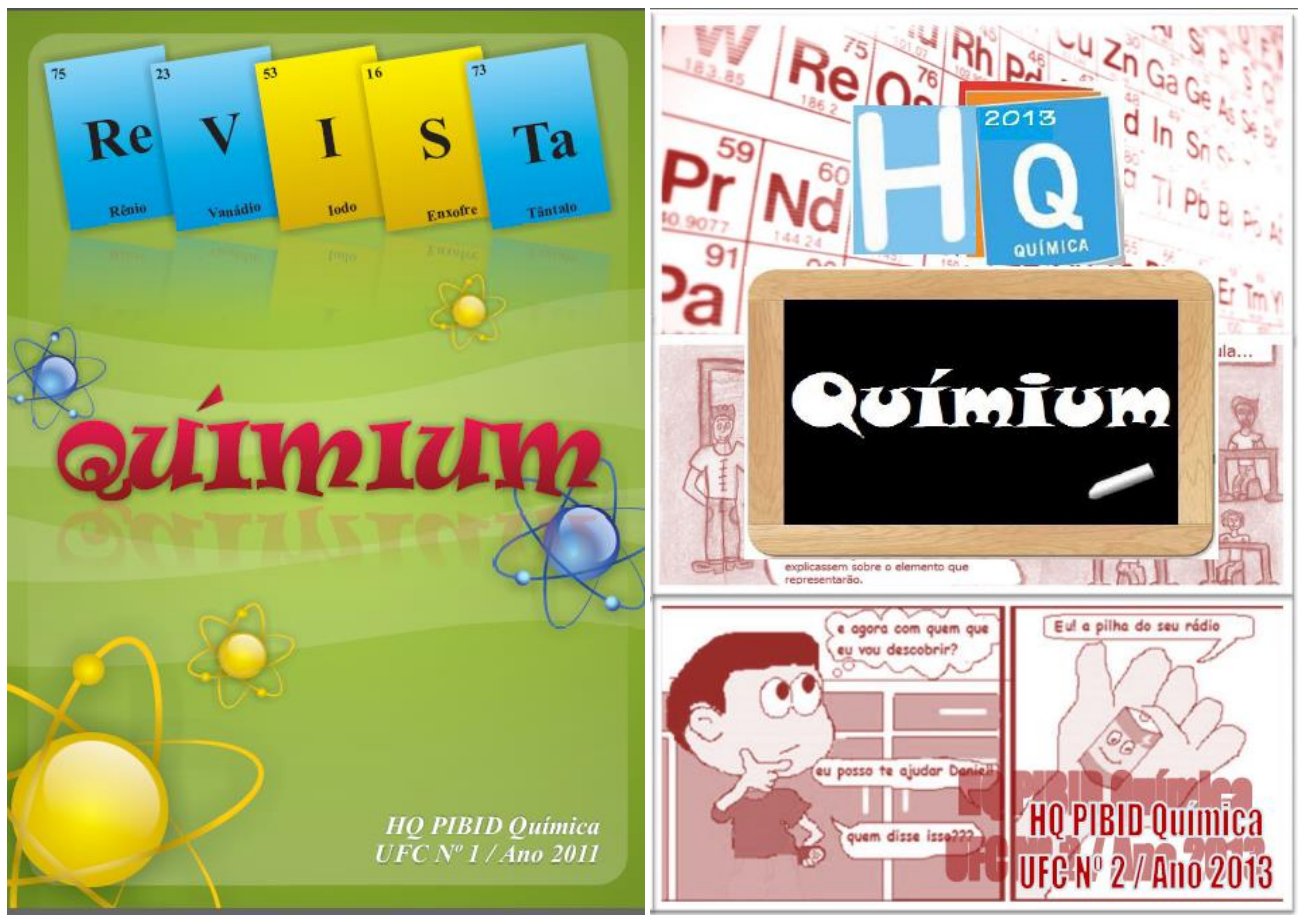

Fonte: Revista Quimium - PIBID Química / UFC

Figura 04- Capas das revistas Quimium - Pibid-Quimica UFC 
Ao final da atividade de confecção das histórias, foram recolhidas opiniões dos alunos sobre a mesma para que se tivesse a visão deles e claro verificar a possibilidade de melhorias e ajustes.

“... E muito interessante, incentivar a nossa imaginação, e gosto pela química. Gostei bastante, espero outros PIBID como esse, e a organização e comprometimento são de futuros professores promissores, umas das melhores ideias que já tiveram em dado esse meu tempo de escola".

Relato de uma aluna do $1^{\circ}$ ano do Colégio Estadual Justiniano de Serpa.

"Muito interessante é um jeito diferente de aprender sobre a química. gostei muito de ter feito esse $\mathrm{HQ}$ junto com a equipe".

Relato de uma aluna do $2^{\circ}$ ano do Colégio Estadual Justiniano de Serpa

Para os estudantes do curso de Licenciatura de Quimica da Universidade Federal do Ceará, os bolsistas do programa, a atividade trouxe grandes benefícios. Ao elaborarem os textos contextualizando os conteúdos, os mesmos trabalharam a escrita, a mediação e a contextualização, tão necessária a uma formação docente atual.

A contextualização segundo Wartha e Alário (2005) é entendida como um dos princípios da organização curricular por meio de temas da vivência dos alunos, que propiciem não somente a ilustração ou aplicação do conteúdo, mas o desenvolvimento de atitudes e valores nas discussões de questões ambientais, econômicas, éticas e sociais. É defendido que os temas abordados na química necessitam de contextualização, uma vez que a Química possui uma linguagem própria, partindo de problemas do cotidiano e daí desenvolver uma visão de mundo mais ampla e capacidade de interpretação de situações. De acordo com os PCNEM (BRASIL, 2000) consegue-se isso mais facilmente ao se contextualizar o ensino usando exemplos universais, locais ou regionais nas abordagens e problematização.

\section{Considerações Finais}

O uso de confecções de HQs apresentou-se um método viável na pratica escolar, não só por atender as recomendações dos PCNs e da nova LDB, mas por ser uma ótima ferramenta para avaliar a aprendizagem do aluno, pois ao elaborar suas histórias eles precisam ter os conteúdos sedimentados para que a mesma tenha sentido, além disso, o uso da comédia ou sátira em alguns casos torna o trabalho mais divertido e interessante para os alunos e, portanto de mais fácil aceitação.

À luz desta pesquisa, ficou evidenciado que o emprego de material lúdico para o ensino de Química é uma estratégia viável. Além de excelente ferramenta para revisar conteúdos, a atividade pode proporcionar uma perspectiva ambiental completamente voltada para o dia - a - dia , isto porque os alunos puderam fazer uma conexão entre assuntos de caráter científico com coisas comuns ao seu cotidiano. A historinha fez com que os alunos aprendessem 'brincando'. Tudo isso inspirado numa concepção de 
educação que vai bem mais além da instrução. Desta forma, a indisciplina, a desmotivação, a falta de atenção, o baixo rendimento e a evasão escolar durante as aulas podem ser diminuídos.

Acredita-se que se bem mediada à atividade é bastante significativa, não passando de um mero entretenimento para os alunos. Pretende-se elaborar uma revista para cada escola envolvida no projeto. Exemplares das revistas foram distribuídos entre os alunos elaboradores e as bibliotecas das escolas, e está sendo empregado como material didático por outros professores da área de Quimica.

\section{Agradecimentos}

Aos bolsistas participantes do Grupo PIBID-Química da Universidade Federal do Ceará do período de 2009 a 2013 que colaboraram com a pesquisa, e que não tiveram seus nomes citados na autoria: Anderson Sousa Vaz, André Luiz Ramos de Moura, Bruno Ventura de Queiroz, Eveline Teixeira de Oliveira, Ismael Duarte Luna, Karla Damasceno Uchôa, Kleniane Feitosa Nogueira, Marcus Vinicius Santos da Silva, Robson Lima Farias, Francisco Tiago da Rocha, Giamwemberg de Almeida Barreto e Wander Delfino.

A CAPES E UFC pela ajuda financeira e institucional.

\section{REFERÊNCIAS BIBLIOGRÁFICAS}

ALMEIDA, F. S.; ATAIDE, M. C. E. S. A Abordagem das Histórias em Quadrinho nos Livros Didáticos de Química. Trabalho apresentado no IV CNNQ / II ENNEQ, 2011. Disponível em <http://www.annq.org/congresso2011/arquivos/1300324507.pdf> (Acessado em 27/10/2014)

BRASIL. Ministério da Educação. Secretaria da Educação Média e Tecnológica. Parâmetros Curriculares Nacionais do Ensino Médio - Ciências da Natureza e suas Tecnologias. Brasília: MEC, 2000. Disponível em: <http://www.portal.mec.gov.br>. (Acessado em 26/10/2014).

CHATEAU, J.; O Jogo e a Criança. São Paulo: Summus, 1984.

FERREIRA, J. M. G. O.; BRANDÃO, E. M.; FIGUEIRÊDO, G. J. A.; FIGUEIRÊdO, A. M. T. A.; Utilização de um Recurso Lúdico no Ensino de Química Confeccionado a Partir de Material Reciclado. Instituto Federal de Educação, Ciência e Tecnologia da Paraíba - IFPB. 62 ${ }^{a}$ Reunião Anual da SBPC, 2010. Disponível em <http://www.sbpcnet.org.br/livro/62ra/resumos/resumos/1669.htm> (Acessado em 28/10/2014).

GUIMARÃES, D.; CABRAL, P.; Repositório de Significados, Conceitos e Definições, 2014 Disponível em < http://www.significados.com.br/ludico/> (Acessado em 27/10/2014). 
ROLOFF, E. M. A importância do Lúdico em Sala de Aula. 2010. Disponível em: <http://ebooks.pucrs.br/edipucrs/anais/Xsemanadeletras/comunicacoes/Eleana-

Margarete-Roloff.pdf> (Acesso em 27/10/2014).

PIBID QUIMICA -UFC ): em http://pibidquimicaufc.blogspot.com.br/

SANTOS, A. F.; FIELD'S, K. A. P.; ARAÚJO, S. C. M.; FIDELIS, H. T.; SILVA, L. T.; Proposta de uma Aprendizagem Divertida Através da Construção de Histórias em Quadrinhos. Instituto Luterano de Ensino Superior - ULBRA. XIV Encontro Nacional de Ensino de Química, 2008.

SILVA, A. M.; Proposta para tornar o ensino de química mais atraente. Revista de química industrial, 731, 7-12, 2otrimestre de 2011.

TESTONI, L. A.; ABIB M. L. V. S.; Um Corpo que cai: As Histórias em Quadrinhos no Ensino de Física, UNIVERSIDADE DE SÃO PAULO, Faculdade de Educação. 158p, il. Dissertação (Mestrado), 2004.

WARTHA, E. J; SILVA, E. L; BEJARANO, N. R. R. Cotidiano e Contextualização no Ensino de Química. Química Nova na Escola, v. 35, n. 02, p. 84-91, 2013.

Submissão: 07/10/2016

Aceite: 02/05/2017 